\title{
A Contribution to Infantile Linguistic
}

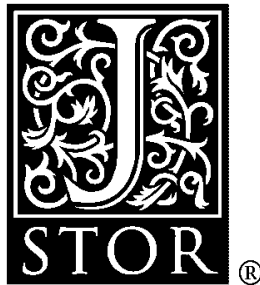

\author{
M. W. Humphreys
}

Transactions of the American Philological Association (1869-1896), Vol. 11. (1880), pp. 5-17.

Stable URL:

http://links.jstor.org/sici?sici=0271-4442\%281880\%2911\%3C5\%3AACTIL\%3E2.0.CO\%3B2-6

Transactions of the American Philological Association (1869-1896) is currently published by The Johns Hopkins University Press.

Your use of the JSTOR archive indicates your acceptance of JSTOR's Terms and Conditions of Use, available at http://www.jstor.org/about/terms.html. JSTOR's Terms and Conditions of Use provides, in part, that unless you have obtained prior permission, you may not download an entire issue of a journal or multiple copies of articles, and you may use content in the JSTOR archive only for your personal, non-commercial use.

Please contact the publisher regarding any further use of this work. Publisher contact information may be obtained at http://www.jstor.org/journals/jhup.html.

Each copy of any part of a JSTOR transmission must contain the same copyright notice that appears on the screen or printed page of such transmission.

The JSTOR Archive is a trusted digital repository providing for long-term preservation and access to leading academic journals and scholarly literature from around the world. The Archive is supported by libraries, scholarly societies, publishers, and foundations. It is an initiative of JSTOR, a not-for-profit organization with a mission to help the scholarly community take advantage of advances in technology. For more information regarding JSTOR, please contact support@jstor.org. 


\title{
TRANSACTIONS
}

OF THE

\section{American Philological Association,}

\author{
1880. \\ I.-A Contribution to Infantile Linguistic. \\ BY M. W. HUMPHREYS, \\ PROFESSOR OF GREEK IN VANDERBILT UNIVERSITY.
}

In some recent works on this subject the rule has been adopted, in making up the child's vocabulary at a certain age, to admit only such words as were actually used during the last month of the period covered, and to form the list by writing each word down when it was used. I have not thought it best to place myself under such restrictions. What we want is the list of words of which the child has command; and if we are sure that it has command of a certain word, such word should not be excluded for the mere reason that the child did not happen to use it during an arbitrarily limited space of time. We could not, for instance, expect a child to happen to use the word "snow" between the $2 d$ of May and the $2 d$ of June.

In the present case, therefore, the following plan has been pursued: When the child was just two years old, aided by its mother I examined the words, one by one, in a dictionary, and marked such words as we were sure the child not only understood, but had spontaneously used, and still could use; 
and whenever there was the slightest doubt, we drew the child into conversation with a view to eliciting the word in question, being careful not to let it hear the word from us; and if we failed to elicit the word at once, we rejected it. In case of a concrete object, I thought it admissible to point at the object and ask, "What is that?" Sometimes the question was settled in regard to verbs also in a somewhat similar manner. For instance, it being a question whether the child had full use of a certain verb, I asked: "What did the kids do this morning?" Answer: "They ran and skipped about."

The vocabulary, then, which I give is that of a little girl, and contains the words, whether correctly pronounced or not, which she had full command of when she was just two years old.

In the works above alluded to, a classification of words according to their initial letters was made, in order to show that ease of pronunciation, especially of those letters, was an important factor in the formation of a vocabulary on the part of a child. But that classification is unscientific. To omit other faults, it is illogical and deceptive to follow the mere written characters of the English, language. The list of words, for instance, beginning with $c$ contains words whose initial sound is $k$, as 'cat,' or $s$, as 'city', or tsh (nearly), as 'chair.' So words seeming to begin with $k$ really begin with $n$, as 'know,' 'knife.' The same is true of some words seeming to begin with $g$; and the $g$ itself represents the $g$ sound proper and also the sound of $j$, and some other letters exhibit analogous facts. In order, therefore, to arrive at any reliable conclusion, the classification should be based upon the initial sounds, and not upon the characters representing the sounds. In the present instance, however, no such classification has been made, for a reason which will be stated.

Although it is not my purpose to enter into any scientific discussion of the development of language in infants, but merely to contribute some material for the use of others, still I shall make a few general statements, some of which are rather of the nature of induction than of observation.

1. We should expect a priori that a child's vocabulary 
would be affected by three considerations: (a) ease or difficulty of utterance, i. e., form; (b) simplicity of the idea, i. e., meaning; (c) frequency of use, i. e., familiarity. As to the first of these-the form of the word-although it had some influence before the child was one year old, when she was two, it had ceased to have any effect whatever. She had, by that time, adopted certain substitutes for letters which she could not pronounce, and words containing these letters she employed as freely as if the substitutes had been the correct sounds. The other two influences-meaning and familiarity -are closely connected, the one leading to the other; that is, the simplest ideas are most frequently expressed. But in many instances, when two words are synonymous, one of them will be used exclusively by a child, because of the rarer employment of the other by persons speaking in the child's presence. Compare, for instance, sparkle and scintillate. And further, it may happen that some local circumstance renders a word familiar, which is generally unknown to children; as, for example, "crinoid"-a word which this child uses every day to designate sections of fossil crinoid stems which abound in neighboring gravel walks.

One phase of the simplicity of ideas should, perhaps, be treated independently as a fourth influence. The same idea may be conceived in a more or a less patent shape. An adjective, for instance, is more readily conceived than an adverb, and a substantive than an adjective. In the case under discussion nouns were most readily seized, then, in order, verbs, adjectives, adverbs, pronouns. Prepositions and conjunctions she began to employ early, but acquired them slowly. Inter jections are of two kinds, natural and conventional. The former, of course, she used to some extent from the beginning (" wah" for instance); the latter came rather late

2. I proceed, in the second place, to give a brief history of the child's linguistic efforts, and I shall have facts to record which may surprise some; but in proportion as they are, or seem, unusual, just in that proportion are they important; for we are always in danger of generalizing from too limited observation, and then carrying with us through life a sort of 
tant pis pour les faits confidence in our theories. A certain scientist in Virginia, attempting to illustrate a beautiful uniformity or periodicity of the annual rainfall, omitted the great rain of September 1870 as being "unprecedented and abnormal" ; and one of our leading physicists once seemed inclined to the belief that I was mistaken, when I told him that in my dreams I could call up scenes and perform experiments, knowing that it was a dream. His theory of dreaming rendered this impossible. If, then, I state that a child at a certain period of its life called cat " $k a \breve{a}$," and $d o g$, "og," from inability to pronounce $t$ and $d$ while it could pronounce $k$ and $g$; let no man say that this is impossible, or even that it is "unprecedented and abnormal," but let him revise his theory.

In the child's linguistic efforts I observed four periods.

(a.) When about four (4) months old she began a curious and amusing mimicry of conversation in which she so closely imitated the ordinary cadences, that persons in an adjacent room would mistake it for actual conversation. The articulation, however, was indistinct, and the vowel sounds obscure, and no attempt at separate words, whether real or imaginary, was made until she was six (6) months old, when she articulated most syllables distinctly without any apparent effort.

(b.) When she was eight (8) months old, it was discovered that she knew by name every one in the house, as well as most of the objects in her room, and the parts of the body, especially of the face. She also understood simple sentences, such as, 'Where is the fire?' 'Where is the baby in the glass?'-to which she would reply by pointing. It was by similar questious that we discovered her knowledge of the names of persons and things. But some things she called by name; so that during this period (from 8 months on, for a few months) she used actual words as words, i. e., as representing ideas, pronouncing some final consonants indistinctly, but initial consonants all clearly except the linguals, $t h, t, d$, $n, l$.

(c.) But she now began a mimicry of language again, this time using real or imaginary words without reference to signification; and in her eleventh (11) month, she learned 
or happened to begin, to pronounce her linguals. She would imitate with accuracy any sound given her, and had a special preference for the nasal palatal $n g$, initial as well as final; and she could reproduce at once syllables beginning and ending with this sound, as ngang, ngeng, nging, ngüng, etc. Of course it made no difference to her whether the vowel sound existed or not, in English or any other language. But about this time it was observed that an obscurity of vowel sounds had begun again; but her consonants seemed perfect, and she had such a fondness for mere imitation of words and sentences, that at one year of age she ceased to use words as words except to a very limited extent, and when she did so, her facility of utterance seemed to have been lost; so that she watched the mouths of others closely when they were talking, and labored painfully after the sounds. This was evidently the result of a conscious effort taking the place of what might be ealled a natural instinct, and her experience in this particular seems to prove that a child's failure to produce certain sounds, as $k$, for instance, is not due to any organic defect or inability, but to want of knowledge how to go about it.

(d.) Finally she began by degrees to drop her mimicry of language, and, at first very slowly, acquired real words with the ordinary infant pronunciation, showing a preference for labials $(p, b, m)$ and linguals $(t, d, n$,-not $l)$ but presently she substituted easy sounds for difficult ones, or rather obvious sounds for hidden ones, and her acquisition of words was then, I fear, almost " unprecedented and abnormal."

3. Her pronunciation during the fourth period was tolerably uniform. The following table presents it as it was from eighteen (18) months to two (2) years :

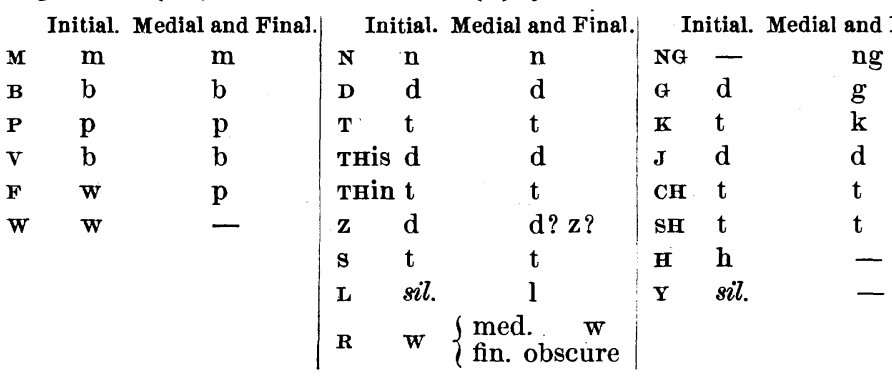




\begin{tabular}{lc|lc|ll}
\multicolumn{7}{c}{} & \multicolumn{3}{c}{ COMBINATIONS. } \\
BL & Initial. & Initial. & \multicolumn{2}{c}{ Initial. } \\
BR & b & TR & t & SN & n \\
PL & b & THR & t & SL & t (for s) \\
PR & p & sP & p & GL & d \\
FL & p & ST & t & GR & w \\
FR & w & SK & t & KW & w \\
DR & w & SW & w & KL & t \\
& d & SM & m & KR & w \\
& & & & HW (wh) hw (h weak)
\end{tabular}

(In these tables the letters represent sounds, not the mere characters with which words are spelled.) Final combinations are omitted. They exhibited phenomena analogous to those of initial combinations. In reference to the latter, it is interesting to observe that when a letter which she could pronounce correctly preceded another, she retained the first; but if both were represented by substitutes, she retained the second. If, however, the second was one which she made silent, then she pronounced the first. Thus $t r=t, k r=w$ (for $r$ ), $k l=t$ (for $k, l$ being one of her silent letters). Her inability to pronounce initial $l$ was very striking, as it forced her to change the pronunciation of her name Lulie (which she had called "Lülü") to "Uelï," which ultimately became "Ullie" ( $u$ in $t u b$ ). Before she was two years old, however, she learned how to pronounce $l$ in all its positions, but did not put it into practical use until later.

She has always had a tendency to carry the accent towards the end of the word if there is a long syllable or a secondary accent there, as "crinoid," "rhubárb," "mantelpiéce," and even in some phrases, as "open it," which, however, proved to be to her a word; for she would say "Open it the door."

4. I was never certain that she invented words. On one occasion, when she was about eighteen (18) months old, a fly flew all about her plate when she was eating, and she exclaimed, "The old fly went wiggely-waggely." The expression, as far as we knew or could ascertain, was original with her.

The use of words with her was, of course, not in all cases the same as with grown persons. She would, for example, say "Good-bye" to anything, no matter how unpleasant it 
was, when she left it. Until her eighteenth (18) month she employed "No" for both "Yes" and "No," and then she substituted "Mam" (from "Yes, ma'am") for "No" in the sense of "Yes," and retained it till she was two (2) years old, using "Yes" only when it was specially suggested to her.

The word "gentleman" she employed to designate a negro man or boy, using " man" for a white man. Her nurse was colored.

5. Her Syntax at the end of two (2) years was very good, including the management of several forms of the subordinate sentence. The character of these sentences is sufficiently indicated by the conjunctions and adverbs in the appended vocabulary.

The first sentence she ever constructed was: "Julia broke the doll "; but she arranged the words in any possible order, frequently repeating the sentence, as: "Julia broke doll,", "Julia doll broke," " Broke doll Julia," etc. This was when she was sixteen (16) months old; and she already knew her verbs so well that she said "broke" (under the form boke), and not "break" or "breakt."

6. In preparing the vocabulary, I have adopted the alphabetical order according to the present English alphabet, merely because it was most convenient to do so, as I used a dictionary. The only attempt at classification is the distribution, under each letter, according to parts of speech. The tabular view at the end will serve for comparison with similar tables that have been made out by others.

It was not in every case easy to decide whether a word should be put down or not. My general method has already been explained. I have not included proper names, nor words (amounting to hundreds) familiar to her only in nursery rhymes, of which she knows a considerable volume. The names of many animals and other objects known to her only in pictures or as toys, are excluded; but I have not, in every instance, felt myself bound to follow the rule of putting down the names only of such objects as she has seen. For instance, she has never seen a lion, or an angel; but she has derived from pictures and toys so definite and vivid a concep- 
tion of these, that they must be recognized as intellectual and linguistic acquisitions, whether her conception of them agrees with ours or not. So, I have included things learned in this way, in cases where the child frequently speaks of them as real objects, apart from their pictures or images.

She knows also many numerals, names of days of the week, etc., which I have omitted, as I could not be certain that she had any definite idea associated with them.

During the six weeks that have elapsed since she was two years old, her improvement in pronunciation, her progress in construction, and her acquisition of new words, have been very rapid; but this does not belong to the present investigation.

VOCABULARY.

A.

n.: ache, acorn, angel, animal, ankle, ant, ape, apple, apron, arm, armhole, ashes, aunt, axe.

v. : ache, allow, am (was, been).

adj.: afraid, all, an (a), another, any, asleep, awake.

adv.: again, ago, all, almost, along, as, away, awhile.

prep. : about, above, across, after, against, around, at.

c.: and.

i., etc. : aha.

B.

n. : baboon, baby, back, bag, baker, ball, balloon, band (of musicians), barber, barrel, basin, basket, bat, bath, bead, bean, bear, beard, bed, bee, beef, beefsteak, bell, belly, bellyache, bell, bench, berry, bib, bird, biscuit, bishop (a mere name), bit, blackbird, blanket, blaze, block', blood, board, boat, body, bone, bonnet, book, bookcase, boot, bottle, bottom, bow (on a dress), bow (with the head), bowl, box, boy, bracelet, bread, breakfast, breast, breeches, brick, bridge, bridle, broom, brother, brow, brush, bubble, bucket, buckle, bud, bug, buggy, bull, bump, bundle, bureau, burn.

v. : baptize, bark, bathe, bawl, be, beat, been, beg, begin, behave, believe, bellow, belong, bend (bent), bite (bit, etc.), blaze, bleed, blow (blew), bother, bounce, bow, break (broke, etc.), bridle, bring (brought), brush, build (built), burn, buy (bought).

adj. : bad, 'bare, barefoot, best, better, big, black, blind, blue, both, brown, busy.

adv.: back, backwards.

prep. : before, behind, but, by.

c. : because.

i., etc. : baa (of a sheep), bang (of a gun). 
C.

n. : cabbage, cage, cake, calf, camel, can, candy, cane, cap, cape, car, card, carpet, carriage, cart, cat, chain, chalk, chamber, cheek, chicken, child (children), chimney, chin, chip, christmas, church, churn, cigar, circle, circus, cistern, city, cloak, clock, cloth, clothes, cloud, clown, coal, coat, cock-roach, colic, cold, collar, color, comb, company, cook, corset, couch, cough, counterpane, cow, crack, cracker (bread), cradle, cranberry, crinoid (fossils in gravel walk), crow, crowd, crumb, cuff, cup, curl, curtain, custard.

v. : call, can (could), cannot, care, carry, catch (caught), chew, choke, clap, climb, comb, come (came), cook, count, crack, crawl, cross, crow, cry, curl, cut.

adj.: clean, cold, cool, crooked, cross, curly.

adv.: close.

n. : daisy, dark, darling, daughter, day, dear, deer, desk, dime, dimple, dining-room, dinner, dirt, dish, doctor, dog, dollar, door, dot, drawer, drawers, dream, dress, drum, duck, dust.

v. : dabble, dance, dangle, die, dig, dip, do (does, did, done), draw (sketch), dream, dress, drink, drive (drove), drop, dry.

adj. : damp, dead, dear, dirty, dry.

adv.: directly, down.

prep.: down.

i., etc. : ding-dong.

E.

n. : eagle, ear, earring, easel, eel, egg, elbow, end, enough, eye, eyebrow.

v.: $\quad$ eat (ate), expect.

adj.: easy, enough, every.

adv.: eas(il)y, enough, ever.

F.

n.: face, fan, father, feather, fellow, fence, fiddle, finger, fire, fireplace, fish, fist, flag, flea, floor, flower, flute, fly, folks, foot (feet), forehead, fork, fox, frog, frost, frown, fuss.

v. : fall (fell), fan, feed (fed), feel, fetch, fight, fill, find (found), fit, fix, fly (flew), fold, follow, forget (forgot), fret, frown.

adj.: fat, fine, fish, first rate, fresh, front (e. g., front door).

adv. : far, fast, first, (in) front.

prep. : for, from.

G.

n.: garden, gaiter, gate, gentleman (i. e., a negro man or boy), giraffe, girl, glass, glove, gnat, God, gold, goose (geese), gourd, gown, grandma, grandpa, grape, grass, grasshopper, gravy, grease, ground, gun, gymnasium.

v.: gallop, get (got), give (gave), go (went, gone), grin, grow, growl, guess.

adj.: : glad, good, great (in “great big”), green.

i., etc. : good-by. 
H.

n. : hair, hair-brush, hair-pin, half, hall, hammer, hand, handkerchief, handle, 'hang-nail, hash, haste (with " make"), hat, hay, head, heap, heart, hearth, heaven, heel, hen, hiccough, hill, hoe, hole, hollow, home, hood, hook, hoop, hooping-cough, horn, horse, house.

v. : hand, hang (hung), hatch, hate, haul, have (has, had), hear (heard), help, hiccough, hide (hid), hit, hold, hollo, hop, howl, hug, hunt (look for), hurry, hurt, hush.

adj.: happy, hard, heavy, high, horrid, hot.

adv.: here, home, how.

pron.: he, her, her (poss.), hers, him, his.

i., etc.: halloo.

I.

n.: ice, ink, iron (i. e., flatiron).

v.: is, itch.

pron.: I, it.

prep.: in, into.

c.: if.

n.: jaw, jay, jelly, joke.

v.: joke, jump.

J.

n.: kettle, key, kid, kiss, kitchen, kite, kitten, knee, knife, knob, knot.

v. : $\quad$ keep (kept), kick, kill, kindle, kiss, kneel, knit, know.

L.

n.: lace, ladder, rady, lamb, lamp, lap, larkspur, leaf, leg, leggin, lemon, lesson, letter (2), light, lilac, line (on paper), lion, lip, little, load, lock, log, lump, lunch.

v. : laugh, lay (laid), leave (left), lend, let, lick, lie (lay), lift, like, listen, live, lock, look, lose (lost), love.

adj.: lame, last, left, light, like, little, long, loose, loud, low.

adv.: like.

\section{M.}

n.: ma'am (madam), mama, man, mane, mantel-piece, marble, mark, market, match, matter, meat, medicine, middle, minute, Miss, mitten, money, monkey, moon, more, morning, mother, mountain, mouse (mice), mouth, much, mud, mug, mule, music, mustache, mutton.

v. : make (made), march, marks, mash, may (might), mean, meet (met), mend, mind, move, must.

adj. : mad, many, mean, more, muddy.

adv.: mighty (= very), more, much.

pron.: me, my, mine, myself.

N.

n.: nail (2), name, neck, needle, negro, nest, Nestlé (prepared food), net, netting, nickel (coin), night, night-gown, nobody, noise, nose, nothing. 
v.: nail, nod.

adj.: naked, nasty, naughty, new, next, nice, no.

adv.: near, no, not, now.

O.

n.: oatmeal, orange, overcoat, owl.

v.: open, ought.

adj.: old, one, open, other, own.

adv.: off, on, out, over.

pron.: our, ours.

prep.: of, off, on, over.

c. : or.

i.: oh.

P.

n.: pail, paint, palm (of the hand), pan, pansy, pants, papa, paper, parlor, parrot, party (at play), path, patch, patience, pea, peach, pebble, pen, pencil, people, pepper, pet, petticoat, picture, piece, pig, pile, pillow, pin, pin-cushion, pipe, pistol, place, plait, plate, plum, pocket, point, poker, pony, porch, pot, potato, powder, prune, puff, pull, pulse (of the arteries), pump, pup, puppy, puss, pussy.

v. : paddle, paint, pat, pay, peck, peel, peep, pet, pick, pinch, pink, play, please, point, pop, pour, pout, preach, pump, push, put.

adj.: pink, poor, precious, pretty.

adv.: presently.

v.: quit.

adj.: quick.

adv.: quick.

i., etc. : quack (of a duck).

Q.

n.: rabbit, rag, rail, railroad, rain, rainbow, rat, reading (print), rest (the), rhubarb, ribbon, rice, ring, road, robin, rock, room, rooster, rope, rose, row, rug.

v. : raise, rattle, read (rěad), reckon, rest, ride (rode), ring (rung), rip, rise (rose), rock, roll, rub, rumple, run (ran).

adj.: ready, red, right (2), ripe, round.

adv.: right, 'round.

prep.: 'round.

S.

n.: sack, saddle, salt, sand, sash, saucer, school, scissors, seam, seat, seed, see-saw, shade, shadow, shawl, sheep, sheet, shelf, shirt, shoe, shoulder, shovel, side, sir, sister, skin, skirt, sky, slate, sleeve, sleigh, slipper, smoke, snake, snout, snow, soap, sock, sofa, soldier, somebody, somerset, something, son, song, soot, sore, soup, spark, spider, spit, splinter, sponge, spool, spoon, spot, spring, squirrel, stable, stairs, star, steam, steam-car, stick, stink, stocking, stool, stopper, store, story, stove, strap, street, 
string, student, study, suds, sugar, sun, sunlight, sunshine, supper, switch.

v.: $\quad$ say (said), scare, scold, scrape, scratch, scream, see (saw, seen), see-saw, send (sent), set, sew, shake, shall, shave, shine, shoot, show, shut, sing (sung), sit (sat), skip (leap), slap, sleep, slide, smell, smile, snap (the finger), sneeze, snow, soil, speak, spill, spit, splash, spoil, squat, squeal, squeeze, stand, stare, stay, step, sting (stung), stir, stoop, stop, strike (struck), suck, swallow, sweep (swept), swim, swing (swung).

adj.: sharp, short, sick, sleepy, smart, small, smooth, soft, some, sore, still, straight, sweet.

adv.: slow (ly), so (2).

pron.: she.

T.

n.: table, tack, tea, tear, thing, thread, throat, thumb, thunder, tie, time, toddy, toe, tongs, tongue, tooth (teeth), toothache, top, town, toy, train (R. R.), trap, trash, tree, trouble, trough, trunk, tuck, turtle.

v.: take (took), talk, tear (tore, torn), tell (told), think (thought), throw (threw), thunder, tie, touch, travel, treat, trot, try, tumble, turn.

adj.: the, thirsty, tight, tired, two.

adv.: then, there, to-day, together, to-morrow, to-night, too.

pron.: that, their, theirs, them, these, they, this, those.

prep.: through, to.

c.: till.

U.

n. : uncle, university (grounds and buildings).

v.: unbutton, undress, untie.

adj. : ugly.

adv.: up.

pron.: us.

prep.: under, up, upon.

n.: vase, veil.

V.

v.: visit, very.

adv.: very.

n. : wagon, waist, waiter, wall, wardrobe, watch, water, way, well, wheel, whip, whiskey, whistle; wind, window, wing, woman, wood, woodpecker, woods, word, work, world (in the), worm, writing.

v. : waggle, wait, wake, walk, wallow, want, was, wash, watch, wear (wore), went, whine, whip, whisper, whistle, will (would), wind (wound), wink, wish, work, wrap, write.

adj.: warm, wee, wet, white, whole, wide, wrong.

adv.: well, when, where, while, why.

pron.: we, what, which (2), who (2), whose (interr.).

prep.: with, without. 
Y.

n.: yard.

adj.: yellow.

adv.: yes.

pron.: you, your, yours, yourself.

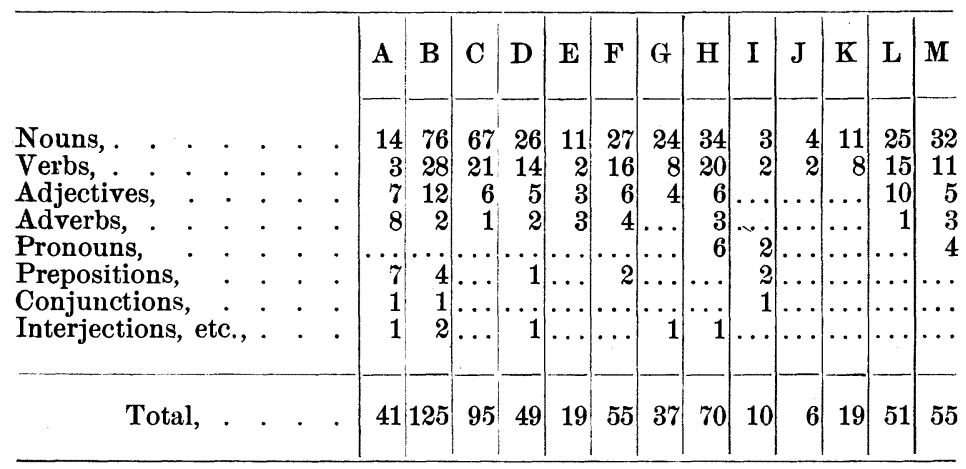

\begin{tabular}{|c|c|c|c|c|c|c|c|c|c|c|c|c|c|c|}
\hline & & & $\mathbf{N}$ & 0 & $\mathrm{P}$ & $Q$ & $\mathbf{R}$ & S & $\mathrm{T}$ & $\mathrm{U}$ & $\mathrm{V}$ & $\mathrm{W}$ & $\mathbf{Y}$ & Total. \\
\hline 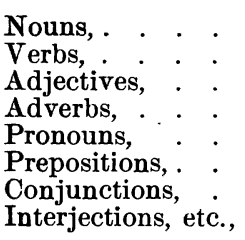 & . & $\dot{v} \cdot$ & $\begin{array}{r}17 \\
2 \\
7 \\
4 \\
\cdots \\
\cdots \\
\cdots\end{array}$ & $\begin{array}{l}4 \\
2 \\
5 \\
4 \\
2 \\
4 \\
1 \\
1\end{array}$ & $\begin{array}{r}53 \\
21 \\
4 \\
1\end{array}$ & \begin{tabular}{r|}
$\cdots$ \\
1 \\
1 \\
1 \\
$\cdots$ \\
$\cdots$ \\
$\cdots$ \\
1
\end{tabular} & $\begin{array}{r}22 \\
14 \\
6 \\
2 \\
\cdots \\
1\end{array}$ & $\begin{array}{r}83 \\
52 \\
13 \\
2 \\
1 \\
\cdots \\
\cdots\end{array}$ & $\begin{array}{r}29 \\
15 \\
5 \\
7 \\
8 \\
2 \\
1\end{array}$ & \begin{tabular}{l|l}
2 \\
3 \\
1 \\
1 \\
1 \\
3
\end{tabular} & $\begin{array}{r}2 \\
1 \\
-2 \\
1\end{array}$ & $\begin{array}{r}25 \\
22 \\
7 \\
5 \\
7 \\
2 \\
\ldots\end{array}$ & \begin{tabular}{r|} 
\\
$\cdots$ \\
1 \\
1 \\
4 \\
$\cdots$ \\
$\cdots$ \\
$\cdots$
\end{tabular} & $\begin{array}{r}592 \\
283 \\
114 \\
56 \\
35 \\
28 \\
5 \\
8\end{array}$ \\
\hline Total, . & & & 30 & 23 & 79 & 4 & 45 & 151 & 67 & 11 & 4 & 68 & 7 & 1,121 \\
\hline
\end{tabular}

In this table irregular verbal and nominal forms are not counted as separate words, except in case of defective verbs, as am, was, been; but the different pronominal forms are counted, and pronominal adjectives are treated as pronouns.

It will be observed that $\mathrm{s}$ begins the largest number, and $\mathrm{c}$ the next largest save $B$; and yet the child cannot utter any initial sound $(s, s h, c h, k)$ represented by $\mathrm{s}$ or by $\mathrm{c}$. 